Research Article

\title{
Teaching System of Embedded Mechanical Manufacturing Specialty Based on Deep Learning
}

\author{
Honghua Liu, WenPing Tan (D), Jingzhong Gong, and Pinghui Hu \\ College of Information and Mechatronical Engineering, Hunan International Economics University, Changsha 410205, \\ Hunan, China \\ Correspondence should be addressed to WenPing Tan; tanwenp2004@163.com
}

Received 28 July 2021; Revised 27 September 2021; Accepted 30 September 2021; Published 21 October 2021

Academic Editor: Sang-Bing Tsai

Copyright (C) 2021 Honghua Liu et al. This is an open access article distributed under the Creative Commons Attribution License, which permits unrestricted use, distribution, and reproduction in any medium, provided the original work is properly cited.

With the increasing development of electronic computers and the popularization of computer technology, management systems have been widely used in the society. With the continuous improvement of the teaching system, the methods of education and teaching are also quietly changing, especially in the field of higher vocational education. Due to the characteristics of vocational education, it makes "training project progress control" and "teaching resource integration" the teaching requirements of "distribution," "strictly restricting daily work habits," "improving professional quality," and "teachers' effective control of the quality of students' personal projects" that have become increasingly urgent needs in vocational colleges. There is a certain gap between the standards and quality of talent training in our country's applied undergraduate colleges, and the society's requirements for high-skilled talents and practical teaching in applied undergraduate colleges are a necessary condition for cultivating high-skilled talent. This subject research takes the mechanical manufacturing professional practice teaching system as the research object, conducts in-depth investigation and research in applied undergraduate colleges, explores the status quo of the mechanical manufacturing professional practice teaching system of applied undergraduate colleges, and analyzes the reasons for the problems. In this study, six classes of mechanical manufacturing majors in six applied undergraduate colleges were selected as the experimental group and the control group for comparison. The experimental group adopts an embedded mechanical manufacturing professional teaching system based on deep learning. In daily teaching, the control group used traditional teaching methods to learn. The questionnaire understands the role of the embedded machinery manufacturing professional teaching system in teaching from four aspects: practical teaching curriculum, practical teaching content, practical teaching equipment, and practical teaching teachers. Experiments have proved that more than half of the people think that the teaching effect of the current mechanical manufacturing professional practice teaching courses is average; only $17.18 \%$ think that the classroom is good, and $24.36 \%$ think that the classroom is poor. This shows that the construction of similar engineering professional practice is in line with the major itself, and the teaching system has theoretical guiding significance, which is conducive to the seamless connection of mechanical manufacturing majors and industrial positions in applied undergraduate colleges; it is conducive to continuously improving the core competitiveness of mechanical manufacturing majors in industrial and applied undergraduate colleges.

\section{Introduction}

In recent years, as the country vigorously develops vocational education, vocational education has achieved unprecedented development, but talent training still cannot meet the changes in job requirements of industry, enterprises, and the needs of social and economic development. Application-oriented undergraduate colleges and universities are particularly prominent in mechanical manufacturing. On the one hand, the technology, skills, and literacy of students trained by the school cannot meet the requirements of enterprises for talent. On the other hand, for the rapid updating and upgrading of machinery industry technology and the large demand for talents, the contradiction between the quantity and quality of school personnel training has become increasingly prominent. The fundamental reason lies in the fact that applied undergraduate colleges ignore practical teaching and lack the necessary conditions for students to carry out practical teaching. In other words, it is the consequence of the imperfection of the practical teaching 
system. However, as far as the current level of vocational education is concerned, if a large amount of innovation is not carried out, it will inevitably result in a shortage of highly skilled talents to meet the requirements of the machinery industry for talent standards, and such vocational education can be sustained.

At this stage, for domestic schools that have opened machinery manufacturing majors, many schools have used CAD teaching software. The current simulation system has relatively large functional limitations and cannot be effectively integrated with other multimedia equipment. It is often used in the teaching process. The functions of uploading courseware and downloading materials are not available. Posadas $\mathrm{H}$ pointed out that the problems existing in practical teaching in applied undergraduate colleges include outdated concepts of practical teaching, outdated practical teaching equipment, lack of characteristics of practical teaching materials, and the construction of teaching staff for practical teaching that needs to be strengthened [1]. Shen $\mathrm{Z}$ believes that, to improve the practical teaching management level of applied undergraduate colleges, the following approaches should be adopted: clear practical teaching objectives of mechanical manufacturing, and timely grasping industry needs and industry frontier information, to enrich the content and methods of practical teaching [2]. Diamond S believes that the goal and philosophy of practical teaching in applied undergraduate colleges should be to improve comprehensive professional ability; in terms of teaching conditions and guarantees, we should focus on the construction of teachers, teaching materials, and training bases [3].

Since the end of the last century, foreign countries have begun to study distance education and training based on computer technology and virtual reality technology. For hardware equipment, simulation equipment is used to replace them, and computer technology is used as the premise to simulate the appearance and function of traditional equipment, realizing the resource data sharing of the system. Ellis DE believes that practical teaching in applied undergraduate colleges should be based on professional competence requirements and establish a target system and build a content system centered on enriching practical teaching [4]. At the same time, it should build a school-enterprise collaborative teaching operation and management system and optimize professional competence as the leading multievaluation system. Garud R pointed out that the construction of the teaching system of applied undergraduate college's needs to be oriented towards cultivating students' ability, and the specific ability requirements of the profession or industry should be run through the practical teaching system [5]. Hebda believes that it is necessary to build a platform that can support practical teaching in applied undergraduate colleges, and it should build an information resource database based on network sharing; integrate resources to build a practical teaching environment suitable for applied undergraduate colleges; and strengthen the full training of practical teaching teachers [6].
This article mainly analyzes the basic content of basic courses for the major of mechanical manufacturing. Study the current teaching status and existing shortcomings, explore ways to use modern educational technology to reform the basic courses of machinery manufacturing, and rebuild a new teaching content system. According to the reconstructed teaching content system of the basic courses of mechanical engineering, under the guidance of modern education thought, teaching theory and learning theory, combined with the development, design principles, and basic theory of the network teaching system, explore the ideal teaching structure and learning under the network environment mode and optimize the design of the network teaching system for basic courses of mechanical engineering. This subject research takes the mechanical manufacturing professional practice teaching system as the research object, conducts in-depth investigation and research in applied undergraduate colleges, explores the status quo of the mechanical manufacturing professional practice teaching system of applied undergraduate colleges, and analyzes the reasons for the problems. The questionnaire understands the role of the embedded machinery manufacturing professional teaching system in teaching from four aspects: practical teaching curriculum, practical teaching content, practical teaching equipment, and practical teaching teachers.

\section{Teaching System of Embedded Mechanical Manufacturing Specialty Based on Deep Learning}

\subsection{Deep Neural Network}

2.1.1. Deep Neural Network Algorithm. Deep learning is currently the most valuable research direction. It is characterized using big data to process signals, which is extremely complex. In this case, it will lead to data redundancy, so deep learning is used to solve such problems [7].

The training data $X=\left\{x_{1}, x_{1}, \ldots, x_{N}\right\}$ represents $N m$ dimensional input vectors. For a deep neural network with $L$ hidden layers, $W^{l}$ and $b^{l}$, respectively, represent the weight and bias of the $l(l=1, \ldots, L)$ layer $[8,9]$. Suppose that the output of the $l$ layer is $h^{l}$, and $h^{0}$ is the input $x$ of the network. A training sample $x$ is input from the input layer, and the feedforward operation of the network can be written as

$$
h^{l}=\sigma\left(h^{l-1}\right) \sigma\left(W^{l} h^{l-1}+b^{l}\right)
$$

$\sigma(\cdot)$ represents the activation function of the neuron. The output of the network is defined as

$$
\begin{aligned}
o & =W^{L+1} h^{L}+b^{L+1}, \\
L(x, y) & =-\frac{1}{n} \sum_{x}(y \ln a+(1-y) \ln (1-a)),
\end{aligned}
$$

where $b$ represents the corresponding parameter. Among them, $a=$ soft $\max (o), y$ are data labels. Then, each data in the training sample $X$ is learned so that the DNN can find a parameter $\theta=\left\{W^{l}, b^{l}\right\}$ to make the loss function as small as possible [10]. 


$$
\left\{W^{l}, b^{l}\right\}=\arg \min _{\theta} \sum_{n=1}^{N} L\left(x_{n}, y_{n}\right), \quad n=1, \ldots, N
$$

2.1.2. Stacked Autoencoder. The output of the $l$ layer is $h^{l}$. The training sample $x$ is sent to the $l$ layer autoencoder for encoding and decoding, which can be written as

$$
\begin{aligned}
& h^{l}=\sigma\left(W_{E}^{l} h^{l-1}+b_{E}^{l}\right), \\
& \tilde{h}^{l}=\sigma\left(W_{D}^{l} h^{l-1}+b_{D}^{l}\right) .
\end{aligned}
$$

Among them, $\theta^{l}=\left\{W_{E}^{l}, W_{D}^{l}, b_{E}^{l}, b_{D}^{l}\right\}$ represents the parameters of the $l$ layer autoencoder. Feature extraction is performed by minimizing the training error between the original data and the reconstructed data, as follows:

$$
L(X, \widetilde{X})=\sum_{n=1}^{N}\left\|x_{n}-\widetilde{x}_{n}\right\|_{2}^{2}, \quad n=1, \ldots, N .
$$

(1) Sparse Autoencoder. The sparse autoencoder includes the sparse constraint of hidden layer activation, which is realized by adding $\mathrm{KL}$ divergence term to the objective function:

$$
J(W, b)=\frac{1}{2}\|x-r\|^{2}+\beta \sum_{j=1}^{k} K L\left(\rho \widehat{\rho}_{j}\right) .
$$

Among them, $k$ is the number of neurons in the hidden layer, and the KL divergence term can also be described as the relative entropy, denoted as

$$
K L\left(\rho \widehat{\rho}_{j}\right)=\rho \log \frac{\rho}{\hat{\rho}_{j}}+(1-\rho) \log \frac{1-\rho}{1-\widehat{\rho}_{j}} .
$$

(2) Shrink Autoencoder. A rule item is added to the error function of the autoencoder, mainly to suppress the disturbance of the training sample in all directions. Its mathematical expression is

$$
\begin{aligned}
J_{\mathrm{CAE}}(W, b) & =\frac{1}{2}\|x-r\|^{2}+\lambda\left\|J_{f}(x)\right\|_{F}^{2}, \\
\left\|J_{f}(x)\right\|_{F}^{2} & =\sum_{i j}\left(\frac{\partial h_{j}(x)}{\partial x_{i}}\right)^{2}=\sum_{i=1}^{d_{h}}\left(h_{i}\left(1-h_{i}\right)\right)^{2} \sum_{j=1}^{d x} w_{i j}^{2} .
\end{aligned}
$$

Among them, $J_{f}(x)$ is the hidden layer output Jacobian matrix with respect to the weight $W,\left\|J_{f}(x)\right\|_{F}^{2}$ represents the square of the Jacobian matrix $F$ norm, and the feature of the hidden layer indicates that it is robust to small changes in the input value [2].

\subsubsection{Clustering}

(1) Self-Organizing Mapping Network. In the training process, the input data is sent to the network through the neurons in the input layer. Input data $X=\left\{x_{1}, x_{1}, \ldots, x_{N}\right\}$, where $N$ represents the number of input data $[3,4]$. In the training process of time $t$, randomly select the $n$ training sample $x_{n}(n=1, \ldots, N)$ from the training data. If the output layer neuron $b$ is the winning neuron, then

$$
b=\arg \min _{i}\left\|x_{n}-w_{i}\right\|, \quad i=1, \ldots, T .
$$

Among them, $\|\cdot\|$ is the distance measurement function, and $T$ is the number of neurons in the output layer. Then, use the update rule to modify the weight vector of the winning neuron $b$ as follows:

$$
w_{i}(t+1)= \begin{cases}w_{i}(t)+a(t)\left[x_{n}-w_{i}(t)\right], & i=b, \\ w_{i}(t), & i \neq b .\end{cases}
$$

Among them, $a(t)$ is the variable learning rate, which gradually decreases with the increase of time.

(2) Gaussian Mixture Model. Regardless of the regularity of the data, multiple Gaussian models based on Gaussian probability density functions can be used for fitting [11]. The Gaussian mixture model refers to a probability distribution model with the following form:

$$
P(x \mid \theta)=\sum_{k=1}^{K} a_{k} \varphi\left(x \mid \theta_{k}\right) .
$$

Among them, $x$ represents a $D$ dimensional continuous value data vector, $K$ is the number of models, $a_{k}$ is the probability of being selected for the $k$ category in the sample set, and $\sum_{k=1}^{K} a_{k} . \varphi\left(x \mid \theta_{k}\right)$ is the Gaussian distribution density, representing the $k$ Gaussian model component, and its function is expressed as

$$
\varphi\left(x \mid \theta_{k}\right)=\frac{1}{\sqrt{2 \pi} \sigma_{k}} \exp \left(-\frac{\left(x-\mu_{k}\right)^{2}}{2 \sigma_{k}^{2}}\right) .
$$

Among them, $\theta_{k}=\left(\mu_{k}, \sigma_{k}^{2}\right)$, mean $\mu_{k}$, and variance $\sigma_{k}^{2}$.

$$
\theta=\left\{\mu_{k}, \sigma_{k}^{2}, a_{k}\right\}, \quad k=1, \ldots, K .
$$

According to the transformation $[12,13]$, GMM can be expressed as

$$
P(X \mid \theta)=\prod_{n=1}^{N} p\left(x_{n} \mid \theta\right) .
$$

Take the logarithm of the GMM likelihood function, and maximize its $\log$ likelihood function as follows:

$$
\max _{\theta} \ln P(X \mid \theta)=\sum_{n=1}^{N} \ln \sum_{k=1}^{K} a_{k} \varphi\left(x \mid \theta_{k}\right) .
$$

The above-mentioned expression regarding the nonlinear function of parameter $\theta$ cannot directly maximize the parameter but uses the maximum likelihood parameter estimation iteration to obtain an expectation maximization algorithm in a special case $[14,15]$. The number of clusters $K$ is preset in the clustering, and then the variable $\operatorname{Pr}\left(k \mid x_{n}, \theta\right)$ is introduced to represent the probability that the $n$ training data comes from the $k$ model, and the posterior probability is calculated as 


$$
\operatorname{Pr}\left(k \mid x_{n}, \theta\right)=\frac{\left(a_{k} \varphi\left(x \mid \theta_{k}\right)\right)}{\left(\sum_{n=1}^{K} a_{k} \varphi\left(x \mid \theta_{k}\right)\right)} .
$$

In each EM iteration, to ensure the monotonic increase of the parameter likelihood value, the following reestimation formula is used:

$$
\begin{aligned}
& \bar{a}_{k}=\frac{1}{N} \sum_{n=1}^{N} \operatorname{Pr}\left(k \mid x_{n}, \theta\right), \\
& \bar{\mu}_{k}=\frac{\left(\sum_{n=1}^{N} \operatorname{Pr}\left(k \mid x_{n}, \theta\right) x_{n}\right)}{\left(\sum_{n=1}^{N} \operatorname{Pr}\left(k \mid x_{n}, \theta\right)\right)} \\
& \bar{\sigma}_{k}^{2}=\frac{\left(\sum_{n=1}^{N} \operatorname{Pr}\left(k \mid x_{n}, \theta\right) x_{n}^{2}\right)}{\left(\sum_{n=1}^{N} \operatorname{Pr}\left(k \mid x_{n}, \theta\right)\right)}-\bar{\mu}_{k}^{2}
\end{aligned}
$$

Among them, $\mu_{k}, \sigma_{k}^{2}$, and $x_{n}$, respectively, point to any element in the quantities $\bar{\mu}_{k}, \bar{\sigma}_{k}^{2}$, and $\bar{x}_{n}$ [16].

\subsection{Construction of the Curriculum Auxiliary Teaching System}

2.2.1. The Specific Design Strategy of the Curriculum Auxiliary Teaching System. First, the layout should be reasonable, and the overall style should be consistent. Each interface may have a different style, but the overall layout should be reasonable, and the style is the same. The position of the text box should be moderate, the color matching should be coordinated, and the intervention of pictures, movies, and animations should be coordinated with the text box $[17,18]$. Generally, the interface design should properly arrange teaching information, operation information, and clearing methods on the screen. To attract the attention of students, you can use reverse display or flashing. The way of clearing information on the screen cannot be ignored. A good way to clear the screen will increase the beauty and stimulate students' interest in learning.

2.2.2. Training Goals and Characteristics of Machinery Manufacturing Majors. With the rapid development of modern manufacturing, the machinery manufacturing industry has become the pillar industry of the secondary industry, and it has also promoted the changes in the connotation and extension of the machinery manufacturing profession $[19,20]$, which is prominently manifested in the demise of low-tech jobs and the increase in high-tech jobs, Enterprises have very high requirements for these new professional positions, and the difficulty of vocational education for mechanical talents is greatly increased. Under this new situation, through these basic courses, students will be trained to master the theoretical knowledge of the major, strengthen the vocational skills training of students in applied undergraduate colleges, and maintain and improve students' process design, processing, testing technology, and management ability, equipment maintenance capabilities.
2.2.3. The Nature of Machinery Manufacturing and Its Teaching Rules. The machinery manufacturing profession trains application-oriented high-skilled talents. Specifically, it trains professional skills rather than academics, and process-based management rather than design-based management professionals. Teaching requires the application of basic theoretical knowledge and the cultivation of practical ability, and the teaching of professional courses should be more targeted and practical [21]. Therefore, the mechanical manufacturing profession should emphasize the applicability and adaptability of the talent model.

\subsubsection{Based on the Current Level of Technological Develop-} ment of Knowledge Economy. The progress of science and technology shows the latest knowledge and scientific achievements, reflects the deepening of human cognition, and is timely incorporated into the core content of vocational education [22]. Various teaching methods emerge one after another. In the continuous enrichment and renewal of teaching activities, advanced technologies such as computeraided equipment, electronic teaching materials, library network resources, and academic database are applied to practical vocational teaching, breaking the previous traditional teaching mode and breaking through the obstacles of region, time, and space, so that the teaching materials of applied undergraduate colleges must adapt to these changes. Application-oriented colleges and universities must change their training objectives and enrich the curriculum model according to the actual needs of the school.

\section{Experimental Design of the Teaching System for Embedded Mechanical Manufacturing}

3.1. Test Subject. In this study, six classes of mechanical manufacturing majors in six applied undergraduate colleges were selected and set as the experimental group and the control group for comparison. The experimental group used the deep learning-based embedded mechanical manufacturing professional teaching system for daily teaching, and the control group used traditional teaching methods. These students spent roughly the same time learning the mechanical manufacturing course [23]. After the application research was over, a total of 300 questionnaires were distributed to all students, all of which were recovered. The results of the statistical questionnaire were analyzed. The questionnaires included practical teaching curriculum settings, practical teaching content, practical teaching equipment, and practical teaching teachers. Understand the role of embedded machinery manufacturing professional teaching system in teaching in all aspects.

3.2. Experimental Method. This study uses the methods commonly used in social survey research to test the questionnaire and make supplements and modifications based on the results of the test and then issues the questionnaire. From the design of the questionnaire to the final 
TABLE 1: Data sheet of evaluation index system for index reliability testing.

\begin{tabular}{|c|c|c|c|c|c|c|}
\hline & Very clear & Clear & General & Not clear & Chaotic & Alpha \\
\hline Practice teaching curriculum setting & 3.74 & 3.64 & 4.51 & 3.23 & 2.89 & 0.8637 \\
\hline Practice teaching content & 3.33 & 3.78 & 4.15 & 3.22 & 3.28 & 0.8362 \\
\hline Practical teaching equipment & 3.72 & 3.70 & 4.72 & 3.48 & 2.88 & 0.7473 \\
\hline Practical teaching teachers & 3.52 & 3.72 & 4.60 & 3.45 & 2.76 & 0.7917 \\
\hline
\end{tabular}

The data come from the actual classroom evaluation of the teaching effect.

determination and review of the questionnaire, it was all carried out and completed under the guidance of relevant experts and scholars. The research tool used in the questionnaire survey method is the questionnaire. This article divides the results of the questionnaire survey into 5 grades to score. Among them, grade 1 means completely disagree, grade 2 means no objection, grade 3 means disagree, grade 4 means agree, and grade 5 means cannot agree more. Score is to judge the degree of agreement with this point of view.

3.3. Establishment of the Model Evaluation Index System. According to the basic characteristics of the viewpoint, the evaluation indicators can be divided into three levels. The first and second levels cannot directly reflect the value of the viewpoint, while the third-level indicators can be used as the basis for evaluation.

3.4. Statistical Data Processing Method. ImageJ 2x software was used to collect the images of Western blotting results, and GraphPad Prism 4 software was used for mapping and analysis. The experimental results are all expressed as mean \pm standard deviation, and SPSS13.0 was used for statistical analysis. $P<0.05$ indicates that the difference is statistically significant.

\section{Experimental Embedded Teaching System of Mechanical Manufacturing}

4.1. Evaluation Index System Based on Index Reliability Testing. According to the experimental process, different indicators can be obtained as shown in Table 1 :

It can be seen from Figure 1 that the data obtained from the settings of practical teaching courses, practical teaching content, practical teaching equipment, and practical teaching teachers have an acceptable impact on this experiment $(\alpha>0.7)$. It can be seen that the scores obtained in this questionnaire survey are credible to a certain extent, and the results obtained this time can be further studied.

\subsection{Survey Results}

4.2.1. Analysis Based on the Setting of Practical Teaching Courses. Practical teaching courses are an effective carrier for applied undergraduate colleges to implement practical teaching. Without practical teaching courses, it is often impossible to implement practical teaching of mechanical design and production majors. The specific conditions are shown in Table 2.
Regarding the setting of practical teaching courses, $55.76 \%$ think that the total number of practical teaching courses offered by our school is less than $20 \%$, and $28.37 \%$ think that the total number of practical teaching courses offered by our school is between $20 \%$ and $60 \%$; only $15.87 \%$ think that the total number of practical teaching courses offered by this school is more than $60 \%$. It can be seen that there are few practical teaching courses for mechanical manufacturing majors in applied undergraduate colleges, as shown in Figure 2.

The effect of existing practical teaching courses is also an important part of the practical teaching system.

Regarding the effect of practical teaching courses, in the survey, we found that as many as $56.13 \%$ of the respondents think that the effect of practical teaching courses is poor; $27.39 \%$ think the effect is fair; and $16.48 \%$ think the effect is relatively good. In the survey, when the practical teaching courses were reasonable, $46.73 \%$ thought that the rationality was relatively poor, $37.43 \%$ thought it was fair, and only $15.84 \%$ thought it was reasonable. The specific situation is shown in Figures 3 and 4.

4.2.2. Analysis Based on Practical Teaching Content. The types of practical teaching in applied undergraduate colleges should cover three forms of school, practical teaching, practical teaching, and productive practical teaching. The specific conditions are shown in Table 3.

Regarding the content of practical teaching, in the survey, we found that the main content of school practical teaching is still mechanical design professional practical teaching, followed by practical teaching, but the proportion is small, and there is almost no productive training. It can be seen from this that the productive training of mechanical design majors in applied undergraduate colleges needs further expansion, and the needs of the teaching content system have been completed. The specific situation is shown in Figure 5.

4.2.3. Analysis Based on Practical Teaching Equipment. The equipment used in the practical teaching courses of the mechanical manufacturing major of applied undergraduate colleges is the basis of practical teaching and the key factor for practical teaching. The specific conditions are shown in Table 4.

Regarding the issue of practical teaching equipment, during the survey, we conducted investigations and studies on the current situation, frequency of use, and permission of use of practical teaching courses. As many as $56.32 \%$ of the respondents believe that the practical teaching equipment for mechanical design majors is insufficient. $23.38 \%$ think 


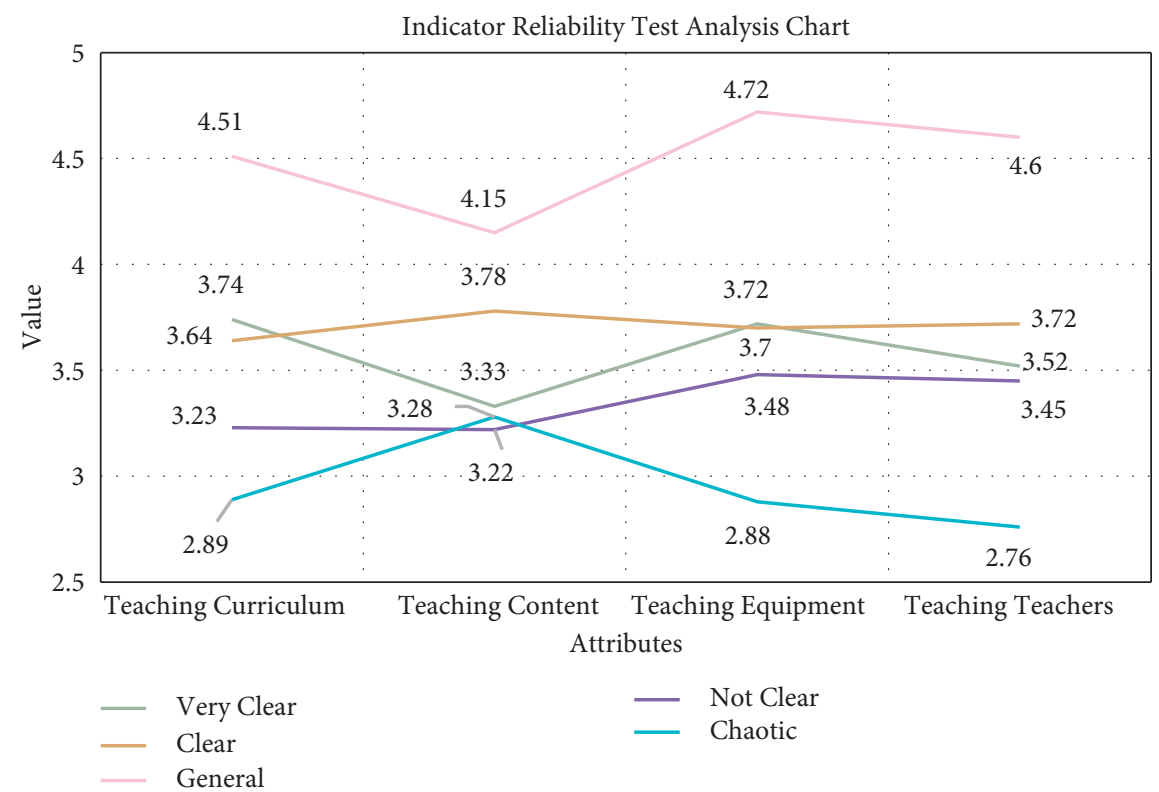

FIgURE 1: Indicator reliability test analysis chart.

TABLE 2: Setting data sheet of practical teaching courses.

\begin{tabular}{lccccc}
\hline Colleges & Less than $20 \%$ & $20 \%$ to $40 \%$ & $40 \%$ to $60 \%$ & $60 \%$ to $80 \%$ & 0.36 \\
A & 3.74 & 4.44 & 4.76 & 0.75 & 0.18 \\
B & 3.51 & 3.58 & 3.80 & 0.48 & 0.55 \\
C & 3.66 & 3.70 & 4.33 & 0.77 & 0.30 \\
D & 3.81 & 4.28 & 4.47 & 0.50 & 0.49 \\
E & 3.7 & 3.98 & 4.04 & 0.31 & 0.22 \\
F & 3.63 & 4.03 & 4.58 & 0.43 \\
\hline
\end{tabular}

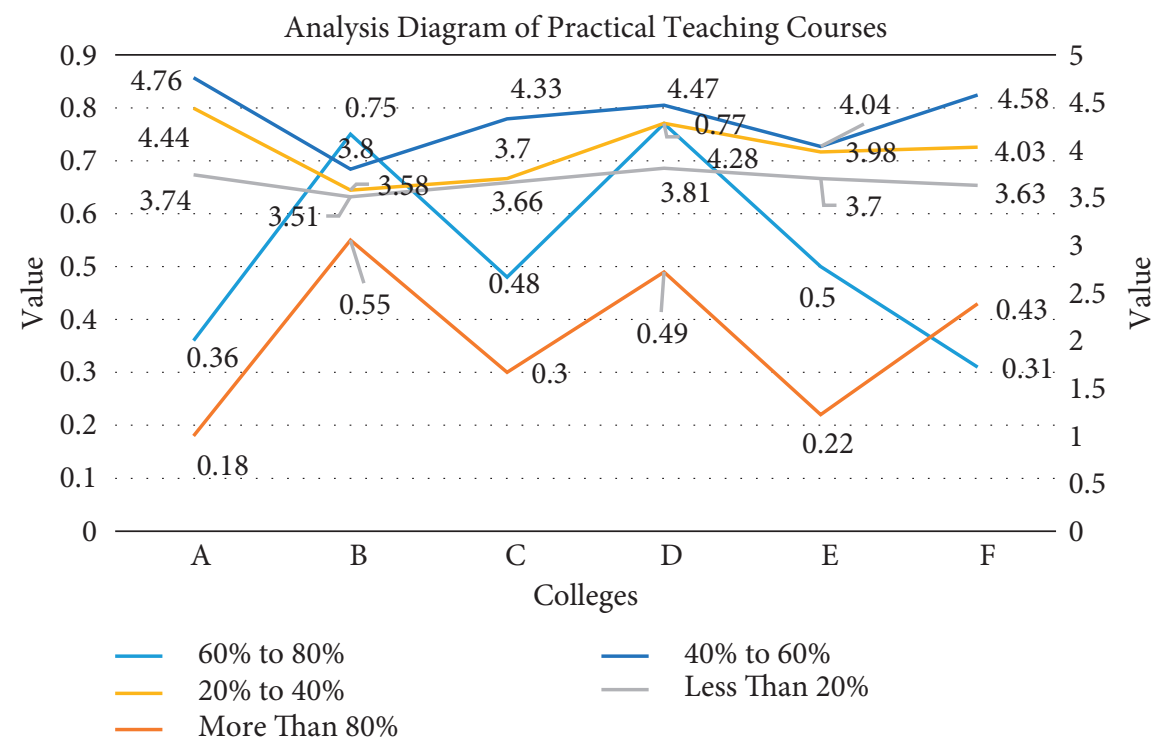

FIgURE 2: Analysis diagram of practical teaching courses.

the number of equipment is okay, and only $20.30 \%$ think the number of equipment is relatively large; the specific situation is shown in Figure 6.
4.2.4. Analysis Based on Practical Teaching Teachers. Practical teaching courses are different from general theoretical courses in applied undergraduate colleges, and, at the 


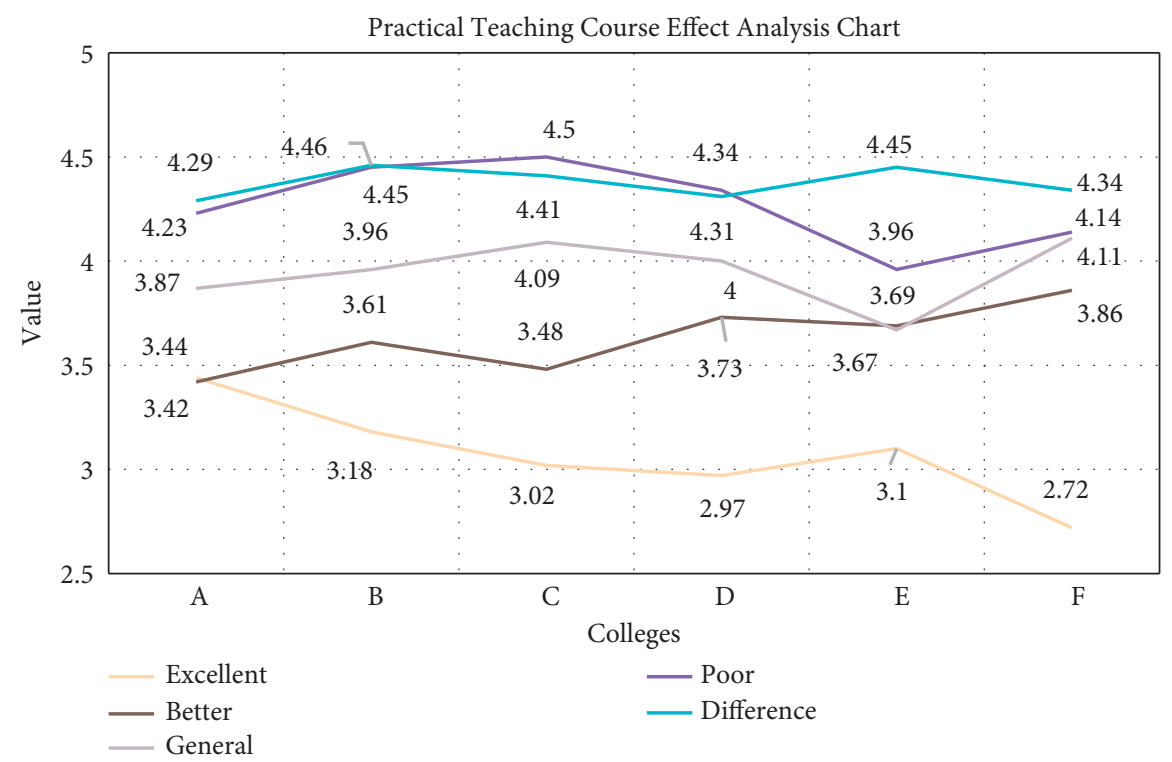

FIgURe 3: Practical teaching course effect analysis chart.

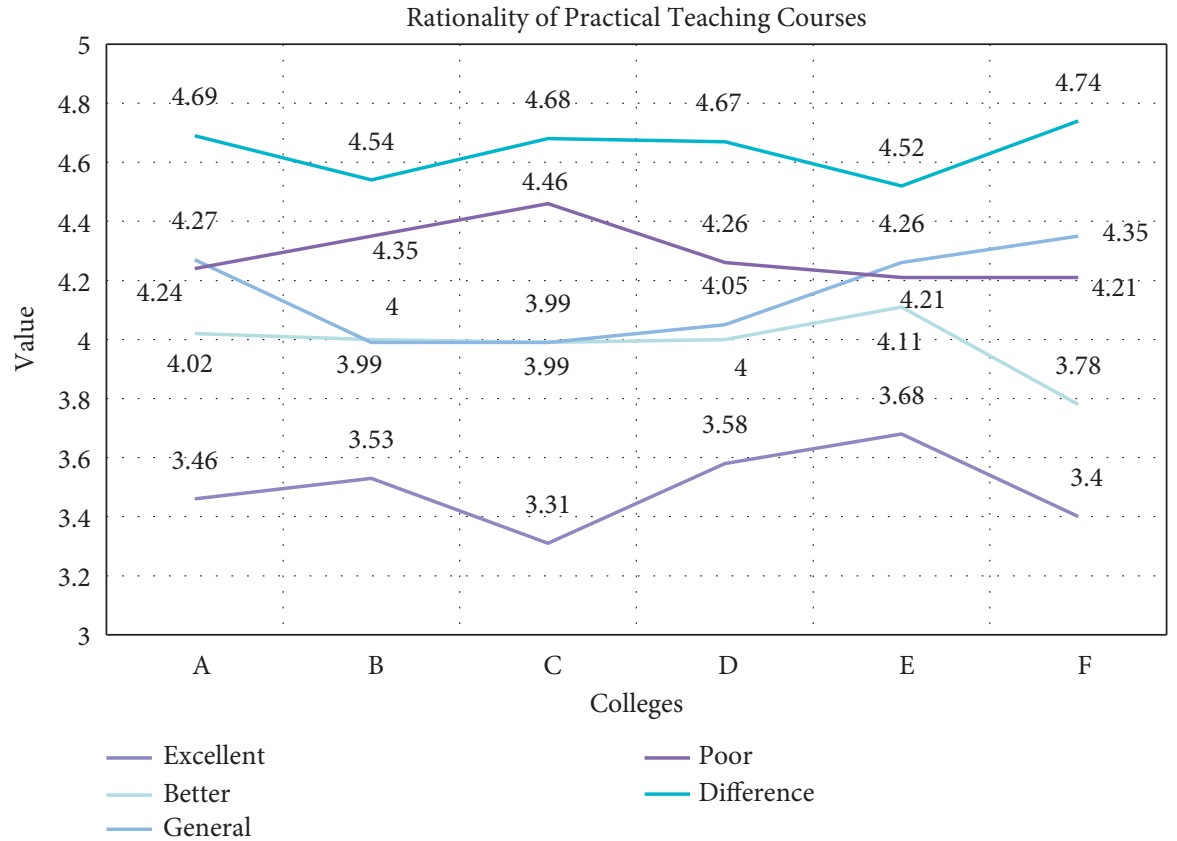

Figure 4: Analysis of the rationality of practical teaching courses.

Table 3: Practice teaching content data sheet.

\begin{tabular}{lccc}
\hline Colleges & School practical teaching & Practical teaching & Productive training \\
\hline A & 4.03 & 0.48 & 0.50 \\
B & 4.03 & 0.72 & 0.12 \\
C & 4.30 & 0.46 & 0.44 \\
D & 4.22 & 0.69 & 0.47 \\
E & 3.88 & 0.78 & 0.23 \\
F & 4.54 & 0.36 & 0.44 \\
\hline
\end{tabular}




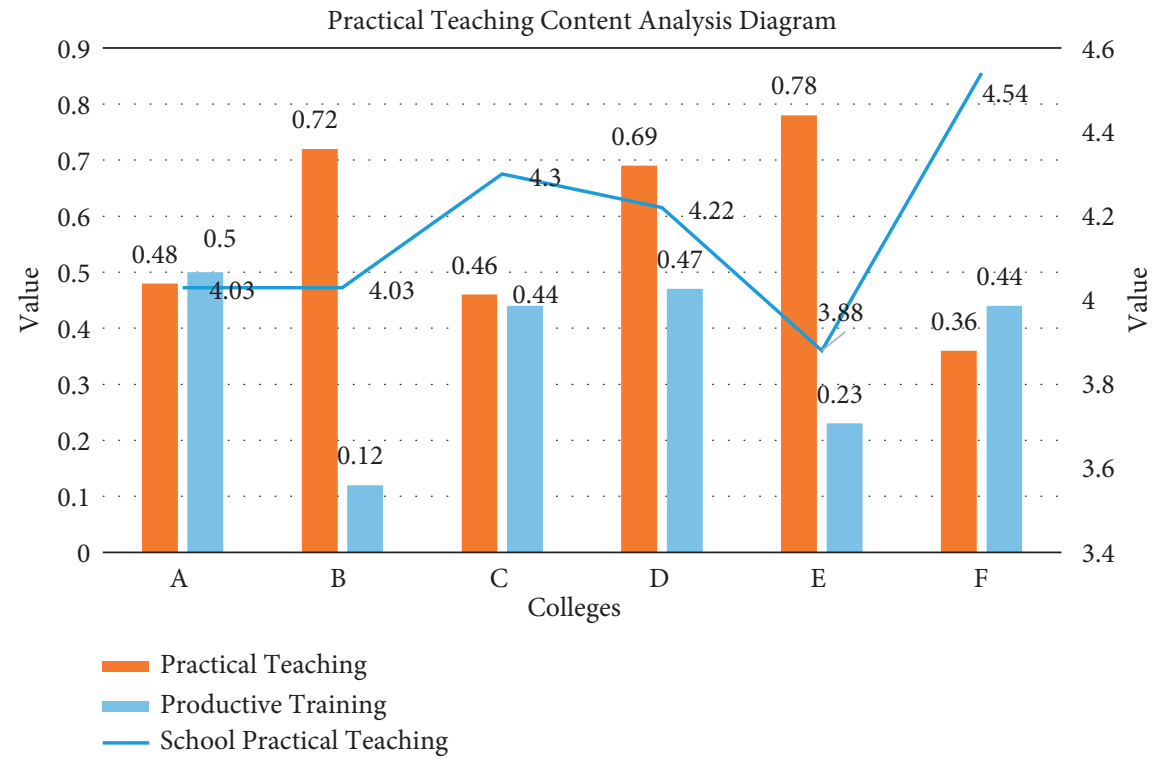

FIgURE 5: Practical teaching content analysis diagram.

TABle 4: Practical teaching equipment data sheet.

\begin{tabular}{lccc}
\hline Colleges & Equipment status & Usage frequency & Usage rights \\
\hline A & 4.63 & 3.94 & 3.47 \\
B & 4.76 & 4.08 & 3.78 \\
C & 4.62 & 3.79 & 3.43 \\
D & 4.70 & 4.08 & 3.56 \\
E & 4.60 & 3.75 & 3.55 \\
F & 4.56 & 3.75 & 3.39 \\
\hline
\end{tabular}

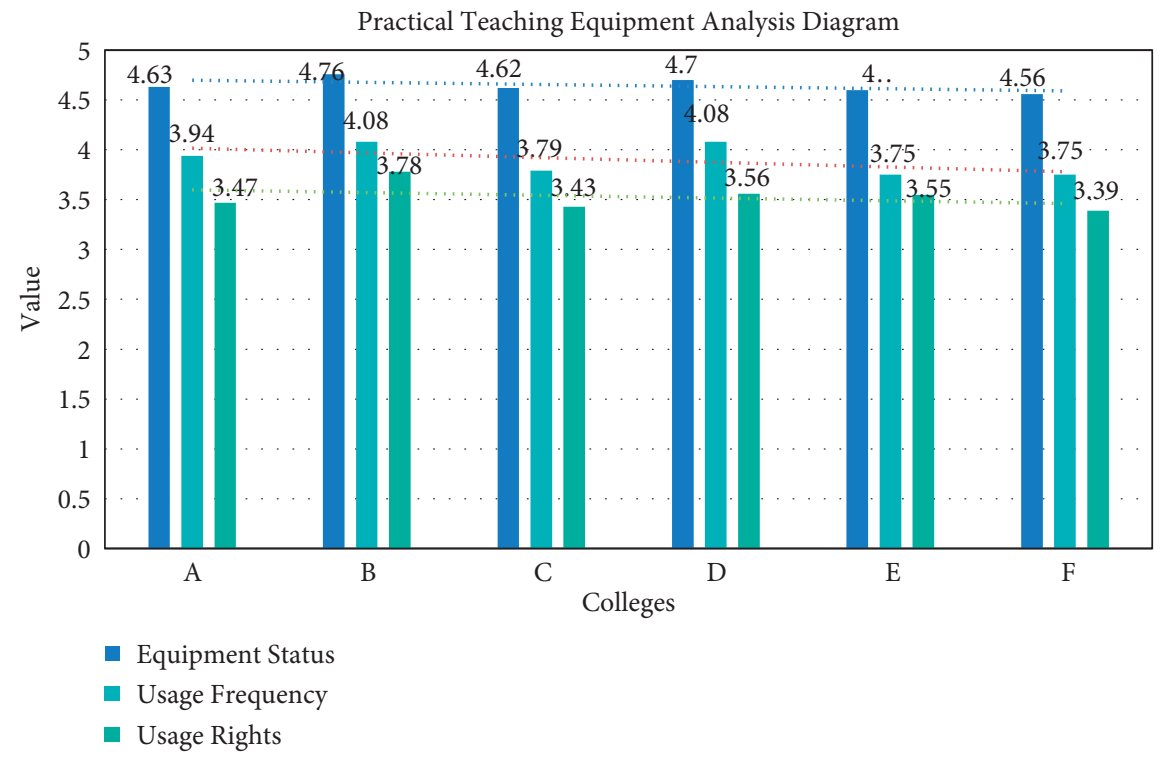

FIgURE 6: Practical teaching equipment analysis diagram.

same time, different from general practical training courses. It is a teaching content that emphasizes the improvement of students' practical ability. This requires teachers to be experts or practical ability experts. Experts and this type of teacher are the key direction of teacher construction in applied undergraduate colleges, and it is also the shortcoming of teachers. The specific situation is shown in Table 5.

Regarding the question of practical teaching faculty, in the survey, we found that $100 \%$ of applied undergraduate colleges and universities lack practical teaching curriculum 
TABle 5: Practical teaching equipment data sheet.

\begin{tabular}{lccccc}
\hline Colleges & Excellent & Better & General & Poor & Difference \\
\hline A & 4.20 & 3.53 & 4.30 & 3.23 & 2.89 \\
B & 3.72 & 3.52 & 4.11 & 3.40 & 3.19 \\
C & 3.76 & 3.82 & 4.75 & 3.00 & 3.02 \\
D & 4.11 & 3.66 & 4.35 & 3.53 & 3.50 \\
E & 3.59 & 3.33 & 4.08 & 3.01 & 3.29 \\
F & 3.44 & 3.57 & 4.65 & 3.20 \\
\hline
\end{tabular}

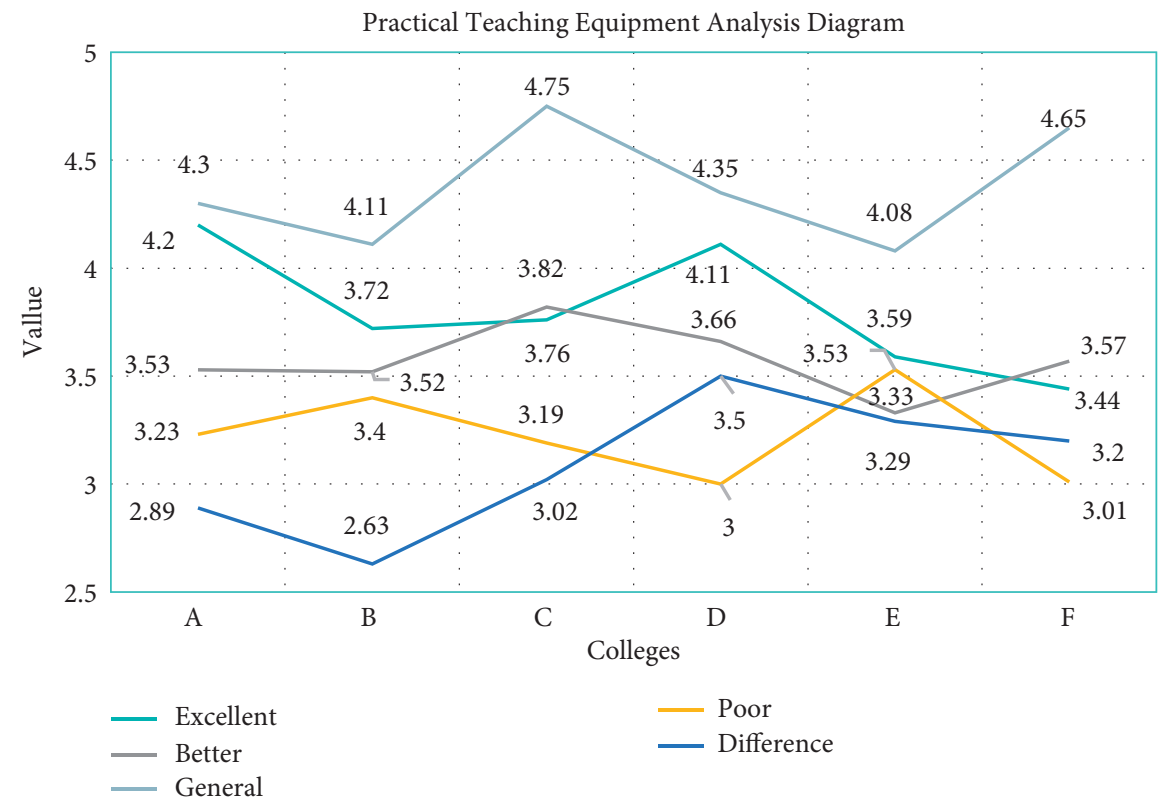

Figure 7: Practical teaching equipment analysis diagram.

Table 6: System function test table.

\begin{tabular}{|c|c|c|c|}
\hline Functional module & Function name & Test steps & Test results \\
\hline \multirow{2}{*}{ Login/registration module } & Registered & Register operation & Successfully registered \\
\hline & Login & Perform login operation & Successfully logged in \\
\hline \multirow{7}{*}{ Main functions of the system } & Setting function & Perform action explanation test & Test success \\
\hline & Task management function & Take action demonstration test & Test success \\
\hline & Task development function & Conduct technical points test & Test success \\
\hline & Production activity function & Perform technical analysis test & Test success \\
\hline & Production query function & Take practice method test & Test success \\
\hline & Call virtual factory environment functions & Perform error correction tests & Test success \\
\hline & Classwork & Take classwork test & Test success \\
\hline
\end{tabular}

teachers, especially excellent technical personnel with corporate work experience. When investigating the teaching effect of teachers in existing practical teaching courses, more than half of the people believed that the current teaching effects of practical teaching courses in mechanical manufacturing majors were average. Only $17.18 \%$ thought the lessons were good, and $24.36 \%$ think that the class is poor, and the specific situation is shown in Figure 7.

\subsection{Testing of the Embedded Machinery Manufacturing Professional Teaching System}

4.3.1. System Function Test. The function of the system mainly includes the main functions such as registration, login, setting function, task management function, task formulation function, production activity function, production query function, and called virtual factory environment function, as shown in Table 6. 


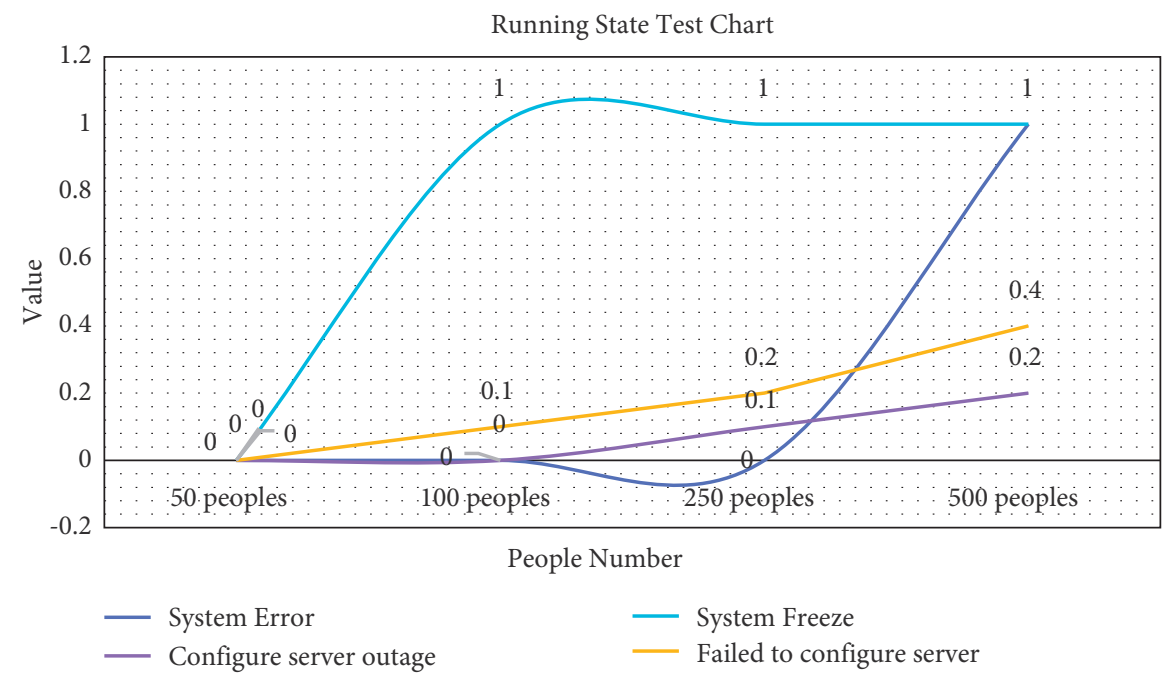

FIgURE 8: Running state test chart.

According to the information in the table, it can be concluded that the test is successful, and the system is operating normally.

4.3.2. Running Status Test Analysis. Test the number of different users, errors, configuration server interruption, or configuration server failures ( 0 means no, 1 means yes). Draw conclusions and analyze and put forward corresponding countermeasures and suggestions on this basis as shown in Figure 8.

According to the data in the figure, it can be seen that when the number of logging in to the system is 100 , the system is not very smooth at the beginning; when the number of logging in to the system reaches 500, the system starts to operate abnormally, and it is performed at the same time when 500 people login operation of the system will not cause the configuration server to be interrupted or the configuration server fails. Therefore, at least 50 people simultaneously log in to the system, and the operating system will not cause excessive lag.

\section{Conclusions}

Aiming at the current situation that the traditional basic curriculum system of machinery manufacturing is not suitable for the current talent training goals, this article puts forward the idea of teaching reform of basic courses of machinery manufacturing. On this basis, a network teaching system for basic courses of mechanical engineering is researched and developed. The knowledge structure and ability structure that machinery manufacturing professionals should have clarify the training objectives of machinery manufacturing professionals, adjust them in time according to the needs of social talents, and highlight the cultivation of students' comprehensive qualities and abilities, so that students can be on a generous basis that there is a broad space for development. In this study, six classes of mechanical manufacturing majors in six applied undergraduate colleges were selected and set as the experimental group and the control group for comparison. The experimental group used the deep learning-based embedded mechanical manufacturing professional teaching system for daily teaching, and the control group used traditional teaching methods. These students spent roughly the same time learning the mechanical manufacturing course. After the application research was over, a total of 300 questionnaires were distributed to all students, all of which were recovered. The results of the statistical questionnaire were analyzed.

The practical teaching system of applied undergraduate colleges is an important part of the education of applied undergraduate colleges and the carrier of talent training in applied undergraduate colleges. It is for optimizing the existing practical teaching system of applied undergraduate colleges and achieving the teaching goals of applied undergraduate colleges. It is of great significance and is a necessary means for application-oriented undergraduate colleges to provide characteristic teaching and improve teaching quality. This study takes students of mechanical manufacturing majors in six universities as research objects and conducts research through literature research methods, survey research methods, and other methods. It is found that the current practical teaching system of mechanical manufacturing majors in applied undergraduate colleges has deviations in practical teaching awareness. The practical teaching curriculum system is unreasonable.

This paper studies the applicability of basic course textbooks for mechanical manufacturing majors in applied undergraduate colleges at a micro level, sorts out related research, and builds applicability evaluation standards for basic course textbooks for mechanical majors in applied undergraduate colleges. We conducted questionnaire surveys and interviews with students and teachers of mechanical manufacturing and automation majors in some applied undergraduate colleges and universities majoring in mechanical manufacturing and automation and found that the textbooks of professional basic courses are applicable to a good degree. However, there are some problems. Some solutions and suggestions are proposed for these problems. 


\section{Data Availability}

The data supporting the results presented in the study are included within the manuscript.

\section{Conflicts of Interest}

The authors declare that they have no conflicts of interest.

\section{Acknowledgments}

This work was supported by Scientific Research Project of Hunan Provincial, Department of Education, under project number 20A287; General Education Project of Teaching Reform in Colleges and Universities of Hunan Province, under project number HNJG-2020-1018; and Hunan Educational Science Planning Project, under project number XJK21CGD047.

\section{References}

[1] H. Posadas and E. Villar, "Using professional resources for teaching embedded SW development," IEEE Revista Iberoamericana de Tecnologias del Aprendizaje, vol. 11, no. 4, pp. 248-255, 2016.

[2] Z. Shen, J. Zhang, G. Chen, and Y. Chen, "On S-quasinormally embedded subgroups of finite groups," Mathematical Notes, vol. 101, no. 3-4, pp. 735-740, 2017.

[3] S. Diamond and S. Boyd, "CVXPY: a python-embedded modeling language for convex optimization," Journal of Machine Learning Research: JMLR, vol. 17, no. 1, pp. 29092913, 2016.

[4] D. E. Ellis, G. A. Benesh, and E. Byrom, "Self-consistent embedded-cluster model for magnetic impurities: Fe, Co, and $\mathrm{Ni}$ in $\beta-\mathrm{NiAl}$," Journal of Applied Physics, vol. 20, no. 3, pp. 1198-1207, 2016.

[5] R. Garud, C. Hardy, and S. Maguire, "Institutional entrepreneurship as embedded agency: an introduction to the special issue," Organization Studies, vol. 28, no. 7, pp. 957-969, 2016.

[6] D. A. Hebda, M. E. Whitlock, J. B. Ditman, and S. R. White, "Manufacturing of adaptive graphite/epoxy structures with embedded nitinol wires," Journal of Intelligent Material Systems and Structures, vol. 6, no. 2, pp. 220-228, 1995.

[7] Z. Lv, K. Amit Singh, and J. Li, "Deep learning for security problems in 5G heterogeneous networks," IEEE Network, vol. 2021, no. 1, pp. 1-8, 2020.

[8] G. Wang, N. Shi, Y. Shu, and D. Liu, "Embedded manifoldbased kernel Fisher discriminant analysis for face recognition," Neural Processing Letters, vol. 43, no. 1, pp. 1-16, 2016.

[9] T. W. Rand and K. C. Yeh, "Transfer functions and pulse distortion for an ionospheric reflection channel with embedded random irregularities," Radio Science, vol. 26, no. 1, pp. 1-14, 2016.

[10] J. He, T. Yu, N. Geng, and L. Carin, "Method of moments analysis of electromagnetic scattering from a general threedimensional dielectric target embedded in a multilayered medium," Radio Science, vol. 35, no. 2, pp. 305-313, 2016.

[11] A. Weiss, S. Gautham, A. V. Jayakumar et al., "Understanding and fixing complex faults in embedded cyberphysical systems," Computer, vol. 54, no. 1, pp. 49-60, 2021.

[12] Plastics information Europe Group, "Plastics sector looks back on good year/Growth above industry average with stellar prospects/machinery manufacturing, 'Industry 4.0 ' and digitalisation drive investments/plastics recycling has potential," Plastics Information Europe, vol. 42, no. TN.1001, pp. 1-2, 2018.

[13] V. A. Skryabin, "Manufacturing parts for hydraulic systems of agricultural machinery under conditions of ultrasonic cutting," Engineering Technologies and Systems, vol. 30, no. 4, pp. 624-636, 2020.

[14] T. Holota, M. H. Holieninová, and M. Kotus, "The use of topsis method in the manufacturing process of clutch plate of agricultural machinery," Agronomy Research, vol. 15, no. 1, pp. 155-161, 2017.

[15] T. Juuti, J. Pakkanen, and T. Lehtonen, "Empirical study of good, bad and ugly modular engineering solutions in machinery manufacturing industry," Proceedings of the Design Society: International Conference on Engineering Design, vol. 1, no. 1, pp. 2981-2990, 2019.

[16] G. N. Sandeva, R. P. Deliradeva, and P. L. Gidikova, "Work ability of machinery manufacturing employees," Journal of Biomedical and Clinical Research, vol. 10, no. 2, pp. 119-125, 2017.

[17] M. M. Alam, M. I. N. Khan, C. K. Saha, and A. Rahman, "Manufacturing of agricultural machinery in Bangladesh: opportunities and constraints," Agricultural Engineering International: the CIGR EJournal, vol. 19, no. 1, pp. 122-135, 2017.

[18] S. Ahmmed, S. M. Farouk, and A. M. Ziauddin, "Status of demand and manufacturing of agricultural machinery in Bangladesh," Agricultural mechanization in Asia, Africa and Latin America, vol. 47, no. 2, pp. 51-54, 2016.

[19] R. Shalini and A. Kumaravel, "Production harmonized reconfiguration of flexible robots and machinery using manufacturing industry 4.0," Journal of Computational and Theoretical Nanoscience, vol. 15, no. 11, pp. 3558-3564, 2018.

[20] R. Dibiano and S. Mukhopadhyay, "Automated diagnostics for manufacturing machinery based on well-regularized deep neural networks," Integration, vol. 58, no. jun, pp. 303-310, 2017.

[21] F. D. L. Nunes, J. A. V. Antunes Júnior, A. Dupont, G. Pires, and D. M. de Quevedo, "Modularisation as a competitive criterion in industries manufacturing machinery and equipment in Brazil," South African Journal of Industrial Engineering, vol. 31, no. 1, pp. 93-109, 2020.

[22] D. B. Hu, C. X. Xiao, and X. H. Chen, "Carbon quotas, subsidies and engineering machinery remanufacturing," Frontiers of Engineering Management, vol. 3, no. 01, pp. 54-62, 2016.

[23] Y. X. Li, Y. Zuo, H. B. Song, and Z. H. Lv, "Deep learning in security of internet of things," IEEE Internet of Things Journal, vol. 2021, no. 8, p. 1, 2021. 